\title{
A Study of the Spiritual Expression of Corridors in Literati Gardens
}

\author{
Tang Fengqiang, Fu Junjie \\ School of Architecture, South China University of Technology, Guangzhou, China \\ Email address: \\ 853616735@qq.com (Tang Fengqiang),1160731903@qq.com (Fu Junjie)

\section{To cite this article:} \\ Tang Fengqiang, Fu Junjie. A Study of the Spiritual Expression of Corridors in Literati Gardens. International Journal of Literature and Arts. \\ Vol. 7, No. 4, 2019, pp. 70-77. doi: 10.11648/j.ijla.20190704.11
}

Received: July 12, 2019; Accepted: August 6, 2019; Published: August 19, 2019

\begin{abstract}
Chinese ancient literati drew inspiration from traditional paintings and pursue picturesque scene in terms of artistic expression in constructing gardens. Using the method of image analysis, literature review, field investigation, and logical analysis, an important element of literati garden construction -- corridor, as the research object, was studied. As the important element of traditional Chinese gardens, corridors in the garden are not only the connection of the buildings, but also act as the guide line of the scenery, which make garden buildings connected into a harmonious whole landscape. Clearly, the interaction between the traditional Chinese painting and garden space were probed from three aspects, spatial order, spatial level and spatial imagination and reality. In sum, spatial-temporal integration, fusion of feelings with the natural setting, interdependence of being and non-being are three levels of the spiritual expression of corridors. Meanwhile, by analyzing the spiritual expression of corridors in the picturesque scene creation of garden space, the paper tries to probe into literati's aesthetic ideals of unity between man and nature and spiritual pursuit of seclusion and detachment. What's more, further studies according to the connotation culture of literati gardens and corridors were probed, in order to provide a reference for contemporary garden practice.
\end{abstract}

Keywords: Literati Garden, Picturesque Scene, Corridor, Space Creation, Spiritual Expression

\section{Introduction}

Ancient Chinese literati pursued the high "unity of man and nature", and had the political ambition and life vision of cultivating moral character, regulating family, managing state affairs and bringing peace to the world. However, most of them with unsatisfactory official career were fettered by the rules of the feudal society for a long period. Influenced by ideas of "emptying hearts" of Daoism and "finding true self" of Zen, literati abandoned themselves to nature by garden-making, and stood by their firm ideals and waited for the opportunity for being an official in good political condition, which was their imagination in predicament [1]. They also recovered their original simplicity for spiritual freedom and detachment, which was a psychological balance mechanism of the literati pursing the best state of being and the optimal development status [2].

Literati created picturesque scenes according to their heart, went in quest of spiritual expression during garden-making and sought the picturesque scene of "Yinghu Fairy Island, a natural picture" [3]. Literati gardens paid attention to idyllic landscape. They created gardens according to poetic sentiment of the poetry used for creating garden artistic conception and inscribing the names of the gardens. By drawing the composition, painters participated in garden-making. Guided by painting theories, the construction of picturesque scenes was highlighted. The ancient literati's painting was similar to garden-making [4]. They got the inspiration of space construction from the expression of spatial order, level and the real and the unreal in traditional painting. In existing studies, many scholars focused on rúhua (如画, 'like a painting') and rùhua (入画, 'captured in a painting') in garden-making. Previous studies discussed the concept that 'viewing a jing was like looking at a painting, and vice versa' [5]. Some scholars paid attention to the interactive relationship between painting and gardening [6], while others studied the role of the openness that garden corridors played in the creation of landscape and site atmosphere [7]. Corridor, as the spatial context in the garden, blended literati's understanding and pursuit of 
spatial-temporal integration, fusion of feelings with the natural setting and interpromoting relation between being and not-being into the garden space that is both material and ideal in the spatial organization, spatial level division and contrast between the real and the unreal.

\section{Spatial Order}

\subsection{Spatial Order of Painting}

From the perspective of visual experience, traditional Chinese painting organizes the spatial order of pictures by cavalier perspective [8]. In the vertical scroll and horizontal scroll, a picture is opened from a macro perspective, and events occurring in different times and scenes are recorded in the picture in the order of unfolding the scroll (Figure 1). Compared with the focus perspective of western painting (Figure 2), no visual focus can be found in the scroll of traditional Chinese painting, and space and time in the picture are dependent on man's will. In the picture, the expression of perspective is discarded, time and space are compressed or stretched, the experience of garden tour is imitated with continuous linear images, and the extension of the picture space implies the change of time.

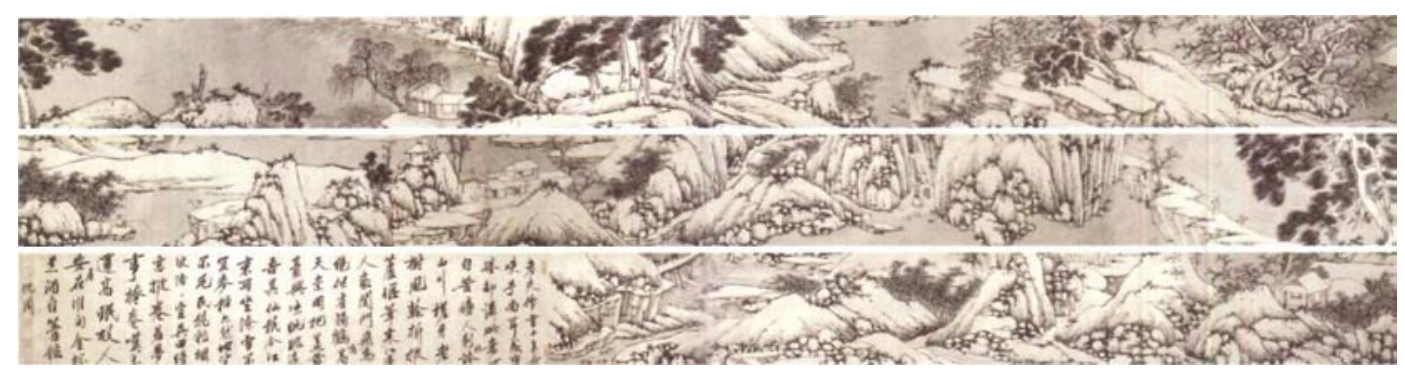

Figure 1. Snowy Mountain by Shen Zhou (Source: Wang Xin. An Architecture Towards Shanshui [M]. Shanghai: Tongji University Press. 2014.17:44).

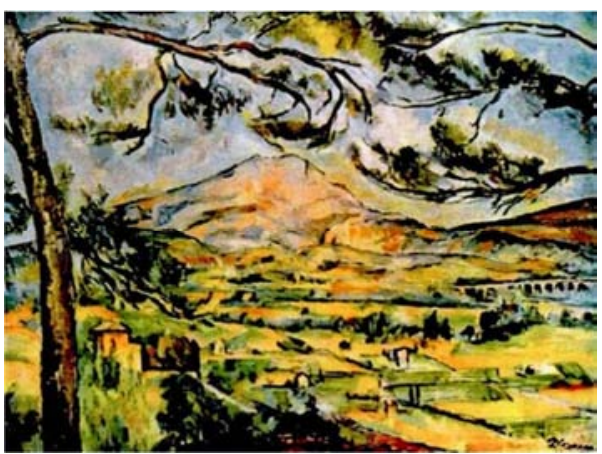

Figure 2. Montagne Sainte-Victoire by Cézanne 1887 (Source: Wang Bingbing. A Study of the Evolution of the Idea of Truth in Cezanne's Painting. From the Series of "Montagne Sainte-Victoire" [D]. Zhejiang University, 2015.).

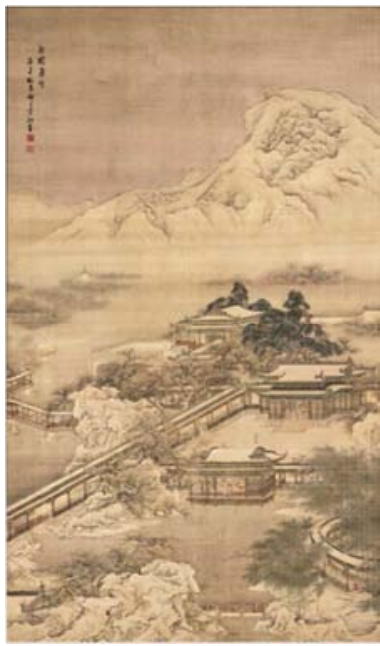

Figure 3. Liang Garden Snowflake Qing Dynasty Yuan Jiang (Source:

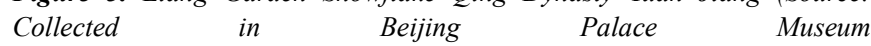
http://ltf.net/img/5766ce0e99e7633df7a3d80d).

\subsection{Corridors and Spatial Order of Gardens}

Just as The Craft of Gardens introduces the corridor "Half way up the mountain and over the surface of the water, different heights, twists and turns, intermittence and winding according to the fluctuation of the terrain are an indispensable part of gardens" corridors as the garden space network connect buildings and space, organize routes and spatial series, and create the experience of varying landscapes with changing perspectives, spatial continuity and spatial-temporal fusion (Figure 3).

Varying landscapes with changing perspectives. Corridors organize pavilions, terraces and open halls, connect mountains, rivers, flowers and trees, arrange landscapes, change perspectives, and convey the visual perception of varying landscapes with changing perspectives. "Every road is accessible". As a kind of narrow linear space, corridors have strong directivity in spite of their twists and turns [9]. Therefore, corridors are the most suitable for organization of landscape order. The spatial organization at the entrance of Zhanyuan Garden guides people into the main scenic spots of the garden by force of the guiding and suggesting functions (Figure 4). The turning point of a corridor leads to the turn of sight, also indicates the turn of space and the change of landscapes and produces the effect of varying landscapes with changing perspectives. In the turn, a corridor must have opposite scenery or expand the space to become the focus of sight. The varying landscapes with changing perspectives create infinite visual perceptions in the limited garden space.

Spatial continuity. Mr. Liu Dunzhen put forward in his book The Classical Gardens of Suzhou that corridors were the veins connecting buildings in the garden, and also often serves as guiding lines for viewing the scenery in the garden [10]. As the spatial frame, corridors organize space, unfold the garden 
space into a plane, and construct a dynamic and complete sequence of garden space including the beginning, development, climax and ending, which shows a continuous sense of spatial rhythm. The spatial experience in the garden is dynamic and continuous, for example, a long narrow corridor in The Lingering Garden is used to connect the low entrance, immediately followed by many turns or shelters, so as to realize sight transfer. Sight is unfolded at the right place at the end of the corridor to see the climax of the sequence. Later, a second turn brings the sequence into the ending. It is thought-provoking. Roads are accessible; corridors lead to the depth of the scenery. Literati created gardens with corridors connecting and organizing garden space. The continuous and dynamic landscape space sequence mobilizes tourists' sensory experience. Spatial continuity promotes the mutual permeation between space and time.
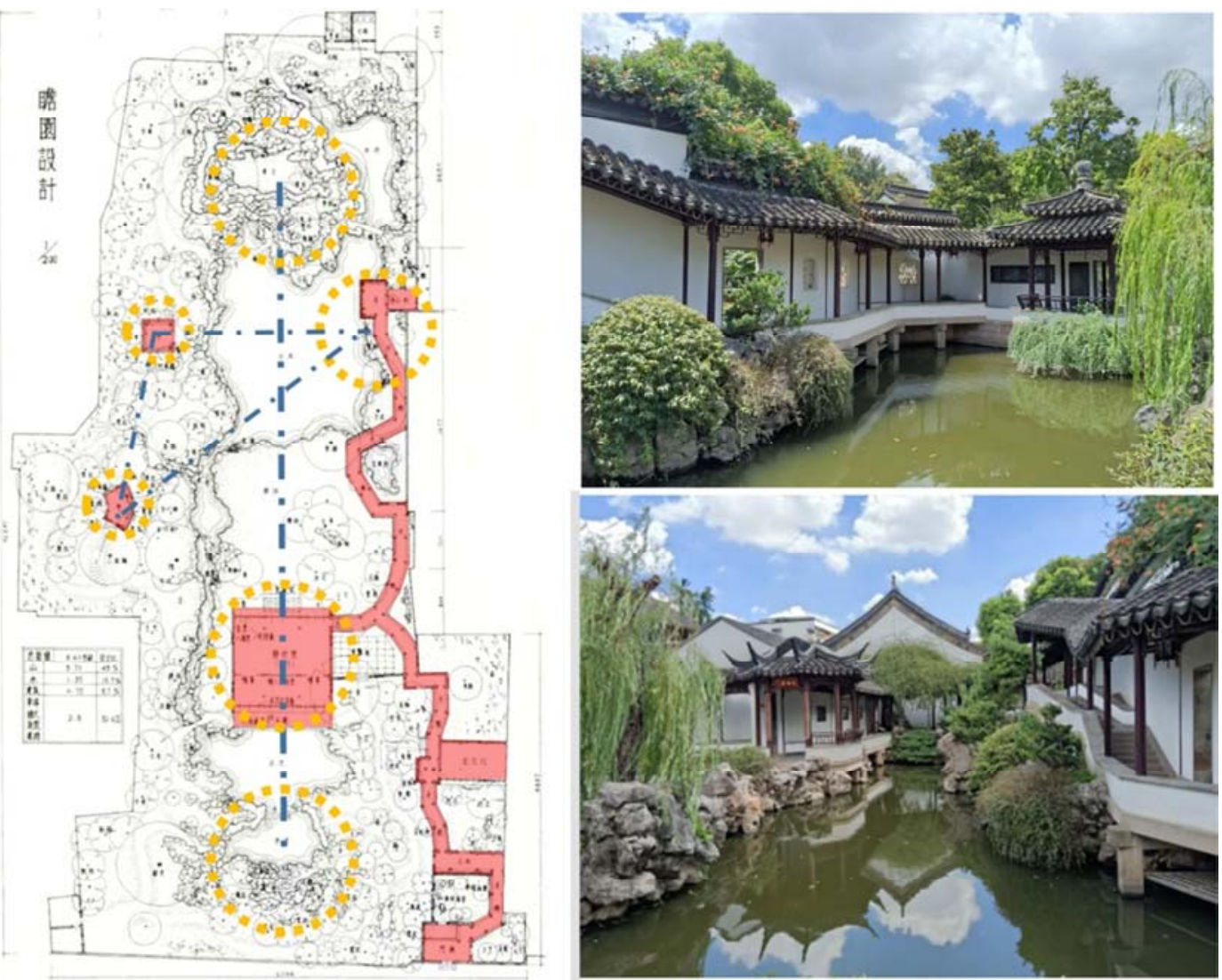

Figure 4. Spatial organization of a corridor in Zhanyuan Garden of Nanjing (Source: Wang Yiting).

Spatial-temporal fusion. Corridors in the garden give people a dynamic experience in the continuous spatial transformation. During the garden tour, space is continuous, while time is blurred. The change of space indicates the passage of time. Gardens organize space with corridors, creating rich space experiences of "twists and turns" and achieving different use purposes and spiritual goals. In Tao Yuanming's An Idyllic Land of Peach-Blossom Spring ${ }^{l}$, "...walked into the opening which at first was found to be so narrow that only one could pass through it. After walking forward for a few footsteps, he discovered that it led to an open air". Under the guidance of the "extremely narrow"

1 An Idyllic Land of Peach-Blossom Spring is one of the representative works of Tao Yuanming, a writer in the Eastern Jin Dynasty. It is the preface of Peach-Blossom Springs and is selected from Tao Yuanming's Collection. This article links the reality with the ideal realm by means of the clue of a Wuling fisherman's whereabouts and expresses the author's ideal of pursuing a better life and his dissatisfaction with the real life at that time by describing the tranquility and happiness of the the Peach Garden as well as the free and equal life. An Idyllic Land of Peach-Blossom Spring is the ideal blueprint of Chinese literati's garden making. "corridor", he thus left his boat and people there had no idea there had been dynasties such as Wei and Jin. Literati are led to their inner homeland. Corridors organize space and create a rhythmic and orderly place. Landscapes present different appearances in different times, but in the continuous space people completely forget the passage of time. Time guides space, while space indicates time in a metaphorical way. Time and space blend together in the dynamic experience.

\subsection{Spatial-temporal Integration}

Literati freely expressed time and space in the traditional painting with their unique wisdom. To organize space, corridors in the garden extend garden space according to time sequence, so the space characterized by objectivity and the time characterized by subjectivity are unified in the garden. Temporal design of a garden should also be closely combined with spatial layout and it also requires to understand people's behavior and mental laws in the process of sightseeing, so that there are plenty of places and landscapes that can be seen, 
visited and rested by the tourists all the time during the visit [11]. One of the characteristics of traditional Chinese garden art is to pay attention to the dynamic time dimension, so "varying landscapes with changing perspectives" is synonymous with temporal design [12]. The space and time in the garden correspond to each other. Literati organized the spatial order through corridors. Rich spatial-temporal experiences are created during the movement of space and the change of sight. They pursued the experience of varying landscapes with changing perspectives, spatial continuity and spatial-temporal fusion. Aesthetic subjects interact with aesthetic objects, creating a picturesque artistic conception and achieving spatial-temporal fusion in the integration of residence and travel. In the pursuit of spatial-temporal integration, corridors organize spatial order, which reflects the literati's consciousness of taking life as the core and their admiration and respect for the spatial-temporal spirit contained in the universe and life.

\section{Spatial Level}

\subsection{Spatial Level in Painting}

Painting is a two-dimensional expression of three-dimensional space, which implies the concept of spatial level. In a book Lin Quan Gao Zhi, Guo Xi emphasized "gāoyuăn" (高远, looking up from the foot of the mountain to the top), "shēnyuăn" (深远, viewing through from the front of the mountain to the back) and "píngyuăn" (平远, looking at the front horizontally from the near mountain to the distant mountain) of the artistic conception of painting space $^{2}$. Landscape painting is not confined to natural landscape sequence, but arranges space for landscapes according to the conception. Landscapes are superposed level by level. By simplifying the outline and weakening the boundary representation, the mutual penetration of space in painting is created. The above "three Perspectives" are not only the rule of space construction, but also literati's spiritual pursuit of self-consciousness. "Far" of the space in the painting indicates the gradual progression of levels from shallow to deep and from surface to inside.

Furthermore, the space of landscape painting includes the expression of spatial depth, breadth and orientation. Although both Chinese and western paintings have tried to show three-dimensional space depth in two-dimensional pictures, their pursuit of depth is different. Western paintings are loyal to the space scene that people can see, while Chinese paintings

2 Lin Quan Gao Zhi is a book written by Guo Xi, which summarizes the experience in landscape painting. It is divided into six chapters, i. e., landscape training, painting meaning, painting strategy, frame collection, painting title and painting notes in addition to the preface. In the process of exploring the artistic beauty of landscape painting, Guo Xi founded "Three Perspectives", that is, "gāoyuăn"(高远, looking up from the foot of the mountain to the top), "shēnyuăn"(深远, viewing through from the front of the mountain to the back) and "píngyuăn"(平远, looking at the front horizontally from the near mountain to the distant mountain), and theoretically explained three kinds of different space processing methods unique to Chinese landscape painting and the beauty of artistic conception and art of composition arising therefrom. try to break through the visual limitations of people and show the effect of "thousands of miles". To the extent that Chinese painting reflects a stronger depth of space. In short, compared with "near", "far" is not just a space concept, which has been endowed with many cultural spiritual connotations by Chinese literati. Consequently, Chinese landscape painting clearly reflects more artistic pursuit. The profound spatial spirit in the painting links with literati's infinite emotion. From scene to emotion, scenes are depicted, literati's spirit is conveyed and images beyond images are explored ${ }^{3}$.

\subsection{Corridors and Spatial Levels of Gardens}

Corridors in the garden have transparent space and tortuous forms. They connect buildings as a transition, divide spatial levels, and create the spatial perception of mutual penetration, rich levels and far-reaching artistic conception.

Mutual penetration. Corridor, as a link between buildings, plays a transitional role in indoor and outdoor space. Buildings are led to a courtyard by corridors. Corridors as the gray space for the transition of indoor and outdoor space has one more layer of transition space than from a building to the other building or from a building to an outdoor courtyard. The "accessibility" of corridors enables sight lines at both sides to communicate, space to be separated but still continuous, and the landscapes to be opposite to each other. The "transparency" enables the space at both sides to penetrate into each other. Like the "phenomenal transparency" depicted in Colin Rowe's Transparency, the spatial attribution of the overlapping part is indistinct because of the fuzzy boundary, making the garden space permeate into each other, something like "you have me; I have you" [13].

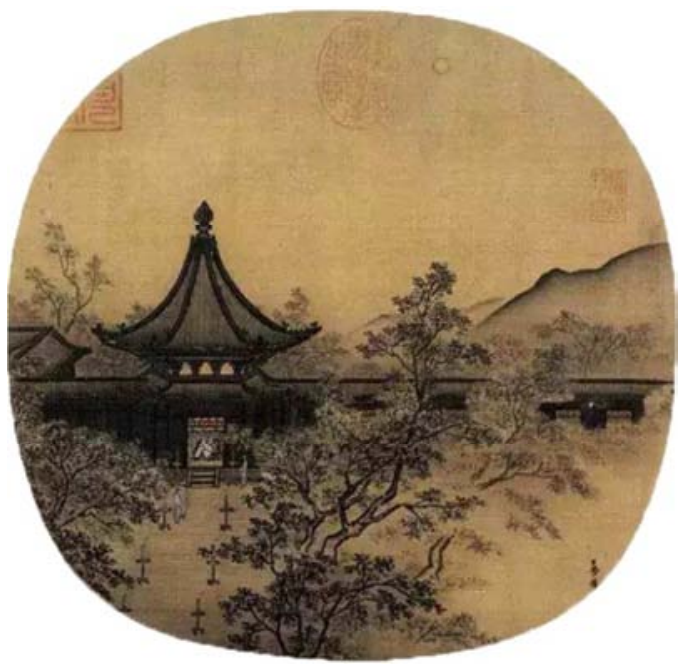

Figure 5. Night Tour by Candle (Source: Duan Bin). Song Painting Landscape Book [M]. Hangzhou: Xiling Press. 2005.)

\footnotetext{
3 "Images beyond images, scene beyond scene" is an aesthetic proposition put forward by Si Kongtu in the Tang Dynasty. The first "images" often break through the boundaries of clear pictures and create a deeper artistic conception beyond the images. The second "images" refer to the most perceptible images directly depicted by poetry works through language and writing with specific shapes, colors and sounds.
} 


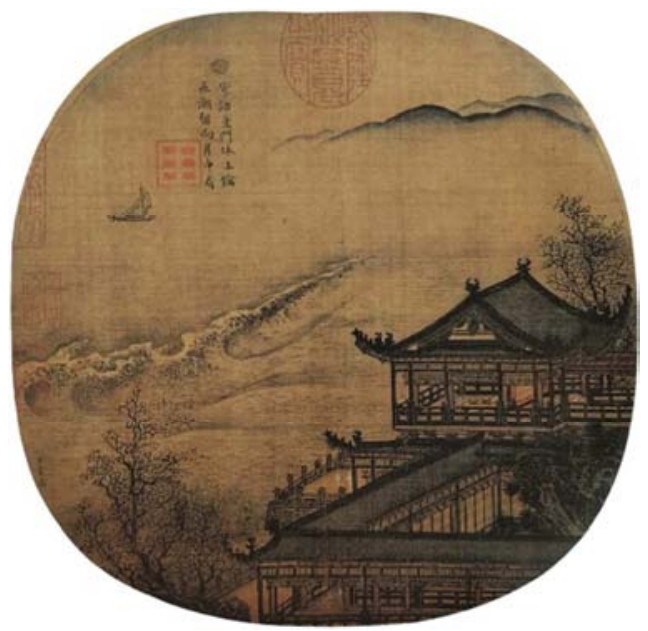

Figure 6. Watching Tide on Moon Night (Source: Classic Series of Masters of Chinese Painting Song Landscape [M]. Beijing: China Bookstore. 2011.)

Rich levels. Corridors in the garden have twists and turns in conformity with the topography. They can form any angle, divide the space in the garden, change infinitely in the linear space, and form rich spatial levels in the garden. The space at the right and left sides of the corridors is transparent. Corridors are medium ground, the landscapes at both sides of which are different. The sight lines are connected through the corridors. The landscapes at both sides mutually become the other's foreground and background, forming rich spatial levels in the front, middle and back. In Ma Lin's Night Tour by Candle in Song Dynasty, corridors divides the picture inside and outside the garden ${ }^{4}$. The distant mountain outside the garden is hazy, and the flowers and trees in the garden are exuberant. The spatial levels are distinct (Figure 5). In $\mathrm{Li}$ Song's Watching Tide on Moon Night in Song Dynasty ${ }^{5}$, corridors divide the space into three levels, namely, small objects in the garden like trees and stones with a higher degree of enclosure, the viewing platform and trees outside the corridors, as well as river water, distant sailboats, distant mountains and so on (Figure 6).

Far-reaching artistic conception. Corridors in the garden divide spatial levels and create far-reaching artistic conception, "Deep, deep the courtyard where he is, so deep". The entrance to The Lingering Garden faces west with the back to $\mathrm{Gu} \mathrm{Mu}$ Jiao Ke (古木交柯). Through the door hole, people can view Huabu Small Courtyard. Across the railing pillars and hangings, the space seems more far-reaching. Also, Small Flying Rainbow in Humble Administrator's Garden separates Songfeng Pavilion and Xiangzhou at both sides, forming rich

4 The style of the corridor in the picture appeared only in the Southern Song Dynasty. The corridor is inlaid with a large number of lattice windows, which were invented after the emperor's south crossing in the Song Dynasty. Lattice windows can be removed for ventilation in the summer, and can be installed for insulation in the winter. So they can solve the problem that the northern aristocracy couldn't bear the southern humidity and coldness.

5 Watching Tide on Moon Night is a silk-based landscape painting created by Li Song in the Southern Song Dynasty. Now it is collected in Taipei Palace Museum. Watching tide in Qiantang was very popular in Song Dynasty. The picture depicts the view of watching sea tide on the autumn night in Lin'an (present Hangzhou, Zhejiang Province) in the Song Dynasty. landscape levels when people view Xiangzhou from Songfeng Pavilion across Small Flying Rainbow. Corridors in the garden divide the courtyard space, which enhances the change of spatial levels in the extension of sight line and the spatial penetration, so that the landscapes can not be seen through at a glance, and the blurred but inexhaustible far-reaching spatial sense can be produced (Figure 7).
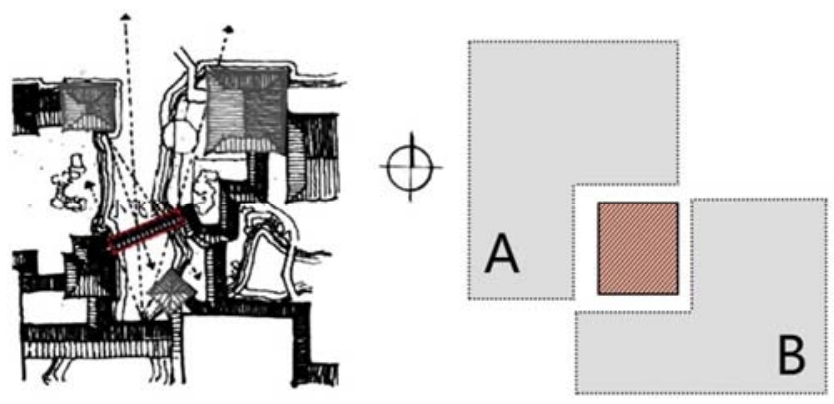

Figure 7. Small Flying Rainbow and Transparent Spatial Intention (Source: Peng Yigang. Analysis of Chinese Classical Gardens [M]. Beijing: China Architecture \& Building Press. 2008: 64)

\subsection{Fusion of Feelings with the Natural Setting (Pursuit and Expression)}

Literati created gardens in pursuit of the picturesque scene of "images beyond images". Corridors are used to divide spatial levels to create the spatial experience of mutual penetration, rich levels and far-reaching artistic conception. The infinite feeling is integrated into the limited scenes, and the infinite spatial artistic conception is pursued. In the painting, spatial spirit is interlinked with literati's emotion. Zhang Zao, a painter in the Tang Dynasty, put forward the artistic creation theory, "Creation comes from the inspiration of nature and the inner feelings" ${ }^{\text {. }}$. Literati had external feelings on the natural, social and cultural environment and integrated emotions into the garden, so as to get inner understandings. Corridors integrate literati emotions into the garden in the construction of spatial levels. Through the fuzzy spatial boundary, the rich spatial levels imply infinite artistic conceptions, that is, there's an end to the words, but not to their message. Garden space is not only the combination arranged by the objects, but also landscape layout arranged through corridors, such as viewing landscapes like appreciating a long-scroll landscape painting. You, in other words, signifies the interactions characterized as relationships and communication [14]. Tourists let eyes travel over the great scenes and let fancy free. They experience the process of change and surprise in the course of the tour, and establish the intimate relationship between man and nature in the process of combining subjective thinking and action. Landscapes are no

6 "Creation comes from the inspiration of nature and the inner feelings", the artistic creation theory put forward by Zhang Zao, a painter in the Tang Dynasty. It is the representative speech of the theory in Chinese aesthetic history. "zào huà" (造 化) refers to nature, "xīn yuán"(心源) refers to author's inner feeling. "Creation comes from the inspiration of nature and the inner feelings", it means that artistic creation comes from learning about Nature, but the beauty of nature can not automatically become the beauty of art. For this transformation process, artists' inner emotion and construction are indispensable. 
longer pure objects, but a fusion of man and scene [15]. "Emotion varies with the change of scenes, and an article is written according to the change of emotions" ${ }^{7}$. It also explains the meaning of a fusion of feelings with the natural setting.

\section{The Real Space and the Unreal Space}

\subsection{The Real Space and the Unreal Space in Painting}

Traditional Chinese painting focuses on the contrast between the real and the unreal. The real and the unreal are a unity of opposites. Sheikh affirmed the role of white space in position management in the Six Laws (liùfã) ${ }^{8}$ of Chinese painting. The large-scale white space in traditional painting often implies the spatial transformation of scenes. Deng Shiru in Qing Dynasty had an extraordinary argument, "Sparse enough to gallop along on horseback, too dense to let in air, reckoning blank as inked"" "The unreal is hard to describe. When the real scenes are clearly painted, the unreal scenes appears naturally. The places without painting become the unreal scenes and form a wonderful realm." This is the function of white space. It can cause unlimited imagination and imply unexpected meaning (Figure 5). Chinese painting expresses meaning through simple line-drawing. The spatial processing of reckoning blank as inked shows the spatial artistic conception of the changing reality. To turn the real into the unreal can make the picture full of sense of space and create the sense of infinite universe. As Pan Tianshou said, "It is not easy to show the real without the unreal. Without the real, the unreal can not exist. No density can be generated without sparseness. Without density, no sparseness can be seen. This is the interpromoting relation between the real and the unreal. That's what painting is like." Chinese landscape paintings often have empty pavilions. Although no one is in the pavilions, the picture is still full of vitality. "The pavilion is empty and unreal and has nothing inside, but people can sit there and see many scenes. The highest level is nothing." 唯 道集虚 reflects Chinese people's sense of the universe [16].

\subsection{Corridors and the Real and Unreal Space of Gardens}

Shen $\mathrm{Fu}$ recorded the real and the unreal artistic conceptions of garden space in his Six Chapter of A Floating Life, "Show the small in the big, and the big in the small, and provide the real in the unreal and for the unreal in the real" [17]. Ji Cheng thought that the combination of the real and the unreal in gardens was the application of the drawing rule of

7 It is the view on the relationship between objects, emotions and culture in the creation of poems in Liang Liuxie's Wen Xin Diao Long in the Southern Dynasty. At different ages, there are different scenes, which have different appearances. Poet's emotions vary with the scenes, and the language is used according to the change of emotions.

8 "Liu Fa" first appeared in Xie He's Quality of Paintings in the Southern Qi Dynasty, and put forward a preliminary and complete framework of painting theory system.

9 "Reckon Blank as Inked" was originally used in calligraphy theory. It means the vacant space (white space) between words is regarded as real painting space (black space). Although no ink is applied, it is still an important part of the overall layout. "yin and yang inter-growth". In the construction of literati garden space, the meaning of the real and the unreal is embodied in many relations. This unity of opposites can carry over to many relations such as emergence, size and density. Wherein, what is observable, dense and big are the real; what is hidden, sparse and small are the unreal. The real and the unreal are produced in the contrast. Corridors organize the space. Through the contrast between the real and the unreal, they reveal something by hiding them, show the small in the big, and achieve the interpromoting relation of the real and the unreal.

Combination of hiding and revealing. Chinese artistic expressions are obscure and euphemistic in pursuit of images beyond images. Garden landscapes can not be seen through at a glance, so there must be something for partition. Corridors organize space, so that landscapes can be revealed in the appropriate time and the appropriate place. Hiding is for better revealing. Literati gardens were often constructed in busy areas. Due to limited land and their intention of creating an open spatial artistic conception in the narrow space, landscapes must be rationally laid out and led by corridors. Where the corridors lead, where the scenery lies. For the spatial organization at the entrance of Humble Administrator's Garden, it is the corridor bridges with the guiding and hinting functions that lead tourists into the main scenic spots of the garden. Corridors do not shelter all and none. Through hangings and corridor pillars, tourists can peep into a corner of the garden. The landscapes flicker, some hidden and some revealed, supplementary to each other.

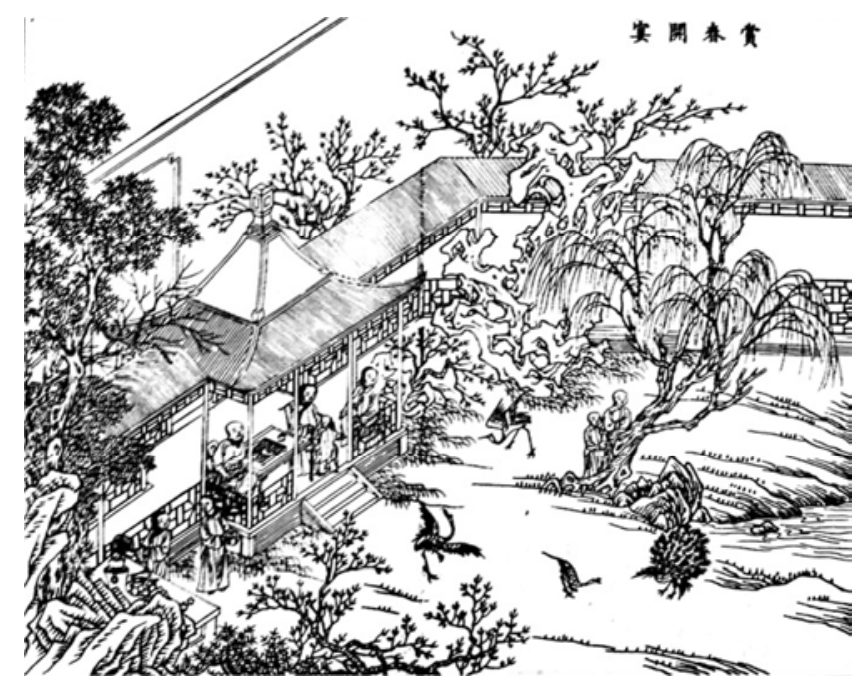

Figure 8. Illustration of Hongxue's Paintings (Source: Chief Editor, Chen Tongbin et al. Great Atlas of Ancient Chinese Architecture [M]. Beijing: China Today Press. 1996.)

Showing the big in the small. "Create a broad sense of mountains and forests in a tiny place and contain everything in a pot". Gardens at the lower reaches of the Changjiang River have limited land, but winding corridors and narrow and long small space serve as a foil to the large space of the central landscapes. In the contrast, the space seems to be magnified. The width of corridors in the garden is generally 1 meter, and their length is usually dozens of meters, far greater than their 
width. So they are long and narrow. The net height of the profiles is often about 2.15 meters, the total height is about 4 meters, and the scale is appropriate. The central landscapes of the garden is more open compared to the corridors. The reduced size of the corridors serves as a foil to the open garden space. The narrowness and openness of space mutually beget each other in the contrast (Figure 8).

Interpromoting relation of the real and the unreal. Lao $\mathrm{Zi}$ expounded the spatial philosophy in Dao De Jing: The Classic of the Virtue of the Tao, "Mold clay into a vessel, from its not-being (in the vessel's hollow), arises the utility of the vessel [18]. Cut out doors and windows in the house (-wall), from their not-being (empty space) arises the utility of the house. Therefore by the existence of things we profit. And by the non-existence of things we are served." The plaster walls in the garden are the real, while the corridors are the unreal. The corridors are the real, while the courtyard is the unreal. Enclosure of the corridors defines the space of the courtyard. The corridor pillars, balustrades and hangings in the garden are the real, while the hollow part in the middle is the unreal. There is the real in the unreal, the unreal in the real, that is, they coexist. "White space" is generated while showing the unreal in the real, and the uni-imagery "images beyond images" are derived (Figure 9).

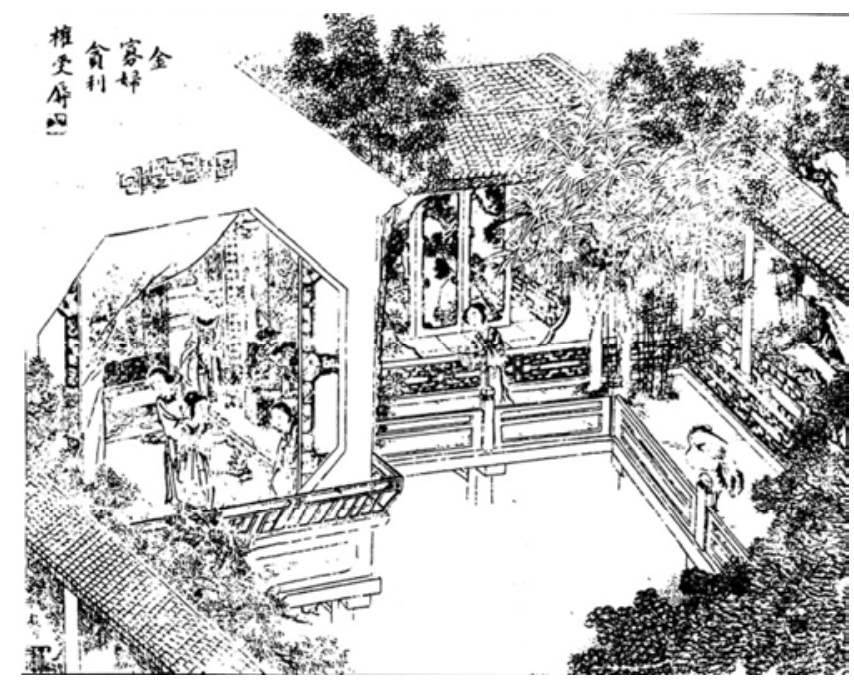

Figure 9. Illustration of Engraving Paintings of Dream of the Red Chamber (Source: Chief Editor, Chen Tongbin et al. Great Atlas of Ancient Chinese Architecture [M]. Beijing: China Today Press. 1996.)

\subsection{Interdependence of Being and Non-being in Growth}

Gardens are important carriers of literati spirit. Corridors in the garden creates space where some scenes are hidden and some scenes are revealed, the big is shown in the small, the real and the unreal promote each other, reflecting literati's pursuit of "nihility" in their inner world and spiritual pursuit of transcendence. "The nameless is the origin of heaven and earth; the named is the mother of all things." ${ }^{10}$ Everything on the earth is generated by being, and being comes from

10 It means that "无" is the origin of heaven and earth and "有" is the root of all things. nothingness. The landscapes in the garden are the real, and literati's emotions are the unreal. The real scenes generate the unreal, and the aesthetic subjects and objects are unified. In painting, freehand brushwork through simple line-drawing and white space as well as both sparse and dense garden space are beyond the description of objective things. In addition, they show literati's emotional experience and thinking about the law of natural evolution. Interpromoting relation of the real and the unreal in the garden space implicates the universal principle of the complementarity of yin and yang, that is, controlling spatial consciousness with universal spirit. "yin and yang making up the Tao"11 embodies literati's universal philosophical view of interdependence of being and non-being in growth.

\section{Conclusions}

The ancient Chinese literati pursued the best state of being and development, that is, "the unity of man and nature". When the ideal of cultivating moral character, managing state affairs and bringing peace to the world was hindered, they tended to seek spiritual sustenance. Painting and garden-making were both important ways for literati to express their inner heart. In the spatial expression, traditional painting attaches great importance to the "harmonious" relationship between man and nature, so that people seem to place themselves in the landscapes. Buildings and environment merge into one, which is in line with the pursuit of the unity between man and nature.

Corridor, as an important structural element and spatial context in the garden, makes a crucial contribution to the construction of the spatial artistic conception of gardens. This paper takes corridors as the research objects, and links traditional Chinese painting and literati garden space through three dimensions of spatial order, spatial level, the real space and the unreal space respectively. Literati got garden-making inspiration from traditional painting, pursued the depth of "images beyond images", and expressed their understanding and pursuit of the unity of space and time, fusion of feelings with the natural setting and interdependence of being and non-being in growth through the spatial organization, spatial level division and the contrast between the real and the unreal space of corridors in the garden, which reflects literati's highest aesthetic ideal of "unity of man and nature" and spiritual pursuit of "seclusion and detachment".

\section{References}

[1] Li Yunhe. Chinese Artists Analysis on the Design Principles of Chinese Classical Architecture [M]. Tianjin: Tianjin University Press. 2005.

[2] Zhang Fa. Chinese and Western Aesthetics and Cultural Spirit [M]. Beijing: China Renmin University of Press. 2010.

\footnotetext{
11 The so-called "The yin and the yang make up the Tao" in The Book of Changes is about the ontology, essence and phenomena of the universe. Ontology is still, and its function is "use and image". Every phenomenon is composed of positive and negative forces, and all things in the world are relative.
} 
[3] (Ming Dynasty) Ji Cheng (Original writer); Chen Zhi (Annotation). Annotation of Yuanye Edition 2 [M]. Beijing: China Construction \& Building Press. 1988.

[4] Tang Xiaoxiang, Wang Yongzhi. Aesthetic Consistency between Traditional Chinese Architecture and Traditional Painting [J]. Hundred Schools in Arts. 2010, (3).

[5] Zou, H. (2002). The jing of a perspective garden. Studies in the History of Gardens and Designed Landscapes, 22 (4), 293-326.

[6] Jin Qiuye, Wang Xin. Wuyou Yuan No.3 Thoughts and Construction [M]. Shanghai: Tongji University Press. 2018.

[7] Li Taiyan. Application Research in Modern Public Space of the Openness of Corridors' Grey Space in Jiangnan Gardens [D]. Lu Xun Academy of Fine Arts. 2019.

[8] Gao Juhan, Huang Xiao, Liu Shanshan. Garden Paintings in Old China [M]. Beijing: SDX Joint Publishing Company. 2012.

[9] Peng Yigang. Analysis of Chinese Classical Gardens [M]. Beijing: China Construction \& Building Press. 2008.

[10] Liu Dunzhen. Classical Gardens in Suzhou [M]. Beijing: China Construction \& Building Press. 2005.
[11] Wu Shuoxian. Temporal Design of Chinese Classical Gardens [J]. Southern Architecture, 2012 (1): 4-5.

[12] Chen Jingjing, Tian Peng, Tian Chaoyang. Preliminary Study on the "French Style" of the Whole Space in the Time Design of Traditional Chinese Gardens [J]. Landscape Architecture, 2015 (8): 125-129.

[13] (Britain) Colin Rowe, Robert Slutzky. Transparency [M]. Beijing: China Construction \& Building Press. 2008.

[14] Han, C. (2012). The aesthetics of wandering in the Chinese literati garden. Studies in the History of Gardens and Designed Landscapes, 32 (4), 297-301.

[15] Xia Yu, Chen Chongxian. Cyclic Evolution Models and Changes of Artistic Conception of Traditional Chinese Gardens [J]. Chinese Gardens, 2015, 31 (10): 116-119.

[16] Zong Baihua. Aesthetic Walk [M]. Shanghai: Shanghai People's Publishing House. 2005: 86.

[17] (Qing Dynasty) Shen Fu. Six Chapters of A Floating Life [M]. Nanchang: Jiangxi People's Publishing House. 1980.

[18] Wang Bi (Annotation). Lao Zi’s Dao De Jing [M]. Beijing: Zhonghua Book Company. 1985. 